\title{
MANEUVERING PERFORMANCE OF TUGBOAT USING COMPUTATIONAL FLUID DYNAMICS (CFD) APPROACH
}

\author{
LIM XUE YEN AND AHMAD FITRIADHY* \\ Program of Maritime Technology, Faculty of Ocean Engineering Technology and Informatics, Universiti \\ Malaysia Terengganu.
}

*Corresponding author: a.fitriadhy@umt.edu.my

http://doi.org/10.46754/umtjur.2021.01.003

\begin{abstract}
Concerning on navigational safety of a ship, comprehensive investigation of manoeuvrability of the ship is prominently required. The turning instability due to improper speed and magnitude of the rudder angle is vulnerable to serious accidents such as collision especially in the confined waters. This paper presents a computational fluid dynamic analyses on manoeuvrability performance of a tug in calm water. Here, the characteristics of the turning ability and zig-zag characteristics of the tug has been assessed due to effect of the various angles of twin-rudder and turning speeds. The results revealed that the increase of rudder's angle resulted in subsequent reduction of her advance diameter from $144 \mathrm{~m}, 108 \mathrm{~m}, 96 \mathrm{~m}$ to $92 \mathrm{~m}$. While for zig zag manoeuvre, the first overshoot angle is $0.6^{\circ}$ and $1.08^{\circ}$ for $10^{\circ} / 10^{\circ}$ and $20^{\circ} / 20^{\circ}$ rudder's angle respectively. The first overshoot and second overshoot angle are within the IMO criteria which is below $20^{\circ}$ and $25^{\circ}$. However, the increase of turning speed from 7 knots to 9 knots has been proportional with the increase of the turning diameter (advance diameter) from $70 \mathrm{~m}$ to $105.2 \mathrm{~m}$. Basically, the turning performances of the tug manoeuvring with the turning speed of 7 to 9 knots incorporated with rudder's angle $20^{\circ}, 25^{\circ}, 30^{\circ}$ and $35^{\circ}$ have been complied with IMO manoeuvring standards. This preliminary analysis contributes very valuable findings at early ship design stage to provide a safety of the navigational guidance for turning ability of the tug.
\end{abstract}

Keywords: CFD, Manoeuvring, zig-zag, rudder's angle; turning speed

\section{Introduction}

Manoeuvrability is defined as the inherent ability of a vessel to change its course or path. Mistakes in speed control and turning velocity of the vessel while using engines and tugs may lead to instability and cause damages or accidents such as collision. Understanding the factor of manoeuvrability of a vessel is extremely important to a designer or a seafarer, along with other aspects such as structural design, machinery, propulsion, stability and seakeeping. Some numerical and experimental investigations on predicting of ship's manoeuvring performances have been established. Moreover, the increase in computer capabilities incorporated with less time consuming and cheaper cost; the use of numerical program methods to predict the manoeuvrability of ship at the initial ship design stage has become possible. Several authors have conducted free-running tests via Computational Fluid Dynamics (CFD) approach for different hulls, such as Hirano et al. (1980) and Ueno et al. (2003). Moreover, turning tests in both regular and irregular waves were performed by Yasukawa (2006) with the ITTC standard S-175 container ship model.

This paper presents a Computational Fluid Dynamic (CFD) simulation used to predict the manoeuvrability of a tugboat in calm water. Here, the commercialCFD called FLOW-3D is used to analyse the turning performance of ship with various angular velocity and speed. The computational domain with adequate numbers of grid meshes specifically for the rudder has been carefully determined. This motion analysis is carried out in a three degrees-of-freedom 
of horizontal plane motions i.e., surge, sway and yaw motions. The effects of the varying rudder angle $(\delta)$ and ship forward speed (U) on the manoeuvring performance of tugboat are taken into account. The results are comprehensively discussed to point out the advance and tactical diameter of manoeuvring fulfil the critical standards of IMO.

\section{Methods and Materials}

\section{Principle Dimensions}

The principle dimensions of the tugboat and twin-rudder that are applied in this simulation are presented in Table 1 and Table 2. The tugboat coupled with twinrudder is design using MAXSURF and CATIA V5 as shown in Figure 1.

Table 1: Principle dimensions of tugboat

\begin{tabular}{lcc}
\hline Descriptions & Model & Full scale \\
\hline Length L, (m) & 0.8 & 40 \\
Breadth B, (m) & 0.178 & 9.0 \\
Draft d, (m) & 0.044 & 2.2 \\
Volume V, (m3) & 0.0003 & 494.7 \\
L/B & 4.44 & 4.44 \\
Block coefficient Cb & 0.62 & 0.63 \\
\hline
\end{tabular}

Table 2: Principle dimensions of rudder

\begin{tabular}{lcc}
\hline Descriptions & Model & Full scale \\
\hline Length L, (m) & 0.04 & 0.2 \\
Draft d, (m) & 0.04 & 0.2 \\
Thickness, (m) & 0.004 & 0.02 \\
\hline
\end{tabular}

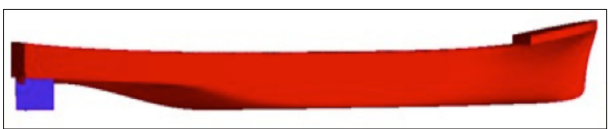

Figure 1: Geometry of tugboat with rudder

\section{Parametric Studies}

In the current CFD simulation, there are three parametric studies have been considered as summarized in Table 3 and Table 4.

Table 3: Rudder's angle for zig zag manoeuvre

\begin{tabular}{lc}
\hline Rudder's angle & Forward speed (knot) \\
\hline $10^{\circ} / 10^{\circ}$ & 7 \\
\hline $20^{\circ} / 20^{\circ}$ & 7 \\
\hline
\end{tabular}

Table 4: Various rudder's angles and forward speeds

\begin{tabular}{cccc}
\hline $\begin{array}{c}\text { Rudder's angle } \\
\left({ }^{\circ}\right)\end{array}$ & \multicolumn{3}{c}{ Forward speed } \\
\cline { 2 - 4 } & 7 & 8 & 9 \\
\hline 20 & $\sqrt{ }$ & - & - \\
25 & $\sqrt{ }$ & - & - \\
30 & $\sqrt{ }$ & - & - \\
35 & $\sqrt{ }$ & $\sqrt{ }$ & $\sqrt{ }$ \\
\hline
\end{tabular}

\section{Computational Domain and Boundary Conditions}

The domain is set up to fit the moving tug to manoeuvre at various speeds and rudder's angle. The mesh generation is set up with nested block. Referring to the main mesh block, the boundary of $\mathrm{X}_{\min }$ is assigned as velocity; while the $\mathrm{X}_{\max }$ is defined as outflow, which is purposed to absorb water flow from $\mathrm{X}_{\min }$ boundary. The boundary for $\mathrm{Y}_{\min }, \mathrm{Y}_{\max }$, $\mathrm{Z}_{\min }$ and $\mathrm{Z}_{\max }$ are assigned as symmetries to minimize the effects of friction loss and surface tension (Fitriadhy et al., 2019). This is similar to all conditions of nested mesh block. The detailed boundary conditions are completely presented in Table 5. 
Table 5: Boundary conditions

\begin{tabular}{cccc}
\hline Boundary & Main Mesh Block & $\begin{array}{c}\text { Nested Mesh Block } \\
\text { (Tugboat) }\end{array}$ & $\begin{array}{c}\text { Nested Mesh Block } \\
\text { (Rudder) }\end{array}$ \\
\hline Xmin & Velocity (V) & Symmetry & Symmetry \\
Xmax & Outflow (O) & Symmetry & Symmetry \\
Ymin & Symmetry (S) & Symmetry & Symmetry \\
Ymax & Symmetry (S) & Symmetry & Symmetry \\
Zmin & Symmetry (S) & Symmetry & Symmetry \\
Zmax & Specified Pressure (P) & Symmetry & Symmetry \\
\hline
\end{tabular}
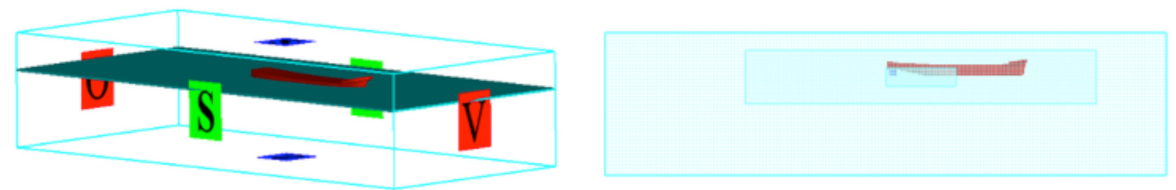

Figure 2: Boundary condition (left) and mesh generation (right)

Meshing for fixed point rotation consists of 3 mesh blocks as clearly shown in Figure 2 (right). In order to increase the quality of meshing, the nested block is highly required. The gridlines of main mesh block and nested block need to align using 2:1 ratio. In this CFD simulation, the main mesh block applied $1 \mathrm{~m}$ cell size with 64,000 total number of cells, the tugboat's nested block applied $0.2 \mathrm{~m}$ cell size with 72,000 total number of cells, and rudder's nested block applied $0.25 \mathrm{~m}$ cell size with 32,000 total number of cells. However, the meshing for zig zag and turning manoeuvre cases only consists of 1 main mesh block; where the cell size is $0.8 \mathrm{~m}$ with 3.15 million and 4.03 million total number of cells, respectively.

Here, the mesh independent study is necessary for examining the adequate number of meshes needed in order to ensure the accuracy of computational results. The result of the mesh independent study shows the total number of cells was about $1,161,750$ in case $C$ has been selected for all computation due to stadiness computation results with less computational time as presented in Table 6 .
Table 6: Mesh independence of study

\begin{tabular}{ccc}
\hline Case & $\begin{array}{c}\text { Total number } \\
\text { of cells }\end{array}$ & $\begin{array}{c}\text { Angular velocity } \\
(\mathrm{rad} / \mathrm{s})\end{array}$ \\
\hline A & 969,400 & 0.038768 \\
B & 988,800 & 0.038697 \\
C & $1,161,750$ & 0.038870 \\
D & $1,577,440$ & 0.039000 \\
\hline
\end{tabular}

\section{Results and Discussion}

The CFD simulations have been successfully carried out to predict the effect of various rudder's angle and operational speed towards manoeuvrability of the tugboat. The yaw motion of tugboat associated various rudder's angle are discussed accordingly in the Sub-sections $3.1 \sim 3.3$.

\section{Effect of rudder's angle to the zig zag manoeuvrability of tugboat}

The zig-zag manoeuvres were carried out for purpose of yaw checking ability which represent the inherent effectiveness of the rudder in making changes of ship's heading. Initially, the rudder's angle is set to change from $10^{\circ}$ port to $10^{\circ}$ starboard $\left(10^{\circ} / 10^{\circ}\right)$ with a forward of 7 knots. As measured in the $10^{\circ} / 10^{\circ}$ zig-zag simulation, 
the first overshoot angle is seen to be relatively small by $0.6^{\circ}$. This means that the result complied with IMO criteria for manoeuvring, in which the first overshoot angle should not exceed $10^{\circ}$ if $\mathrm{L} / \mathrm{U} \leq 10$ sec, where L is ship's length in meter and $\mathrm{U}$ is the forward speed in meter/sec. For the second overshoot angle is obtained about $0.6^{\circ}$, which also complied with IMO criteria i.e., it should not exceed by $\mathrm{L} / \mathrm{U} \leq$
25 sec. In addition, the yaw checking time for the first and second overshoot angle are $1.9 \mathrm{sec}$ and $2.2 \mathrm{sec}$, respectively. In the case of $20^{\circ} / 20^{\circ}$ zig-zag simulation, it shows that the first overshoot angle also complied with IMO criteria which is $1.08^{\circ}$. Furthermore, its yaw checking times is 3.1 sec. In general, $10^{\circ} / 10^{\circ}$ and $20^{\circ} / 20^{\circ}$ zig-zag manoeuvrability of tugboat are acceptable with IMO manoeuvring standards.

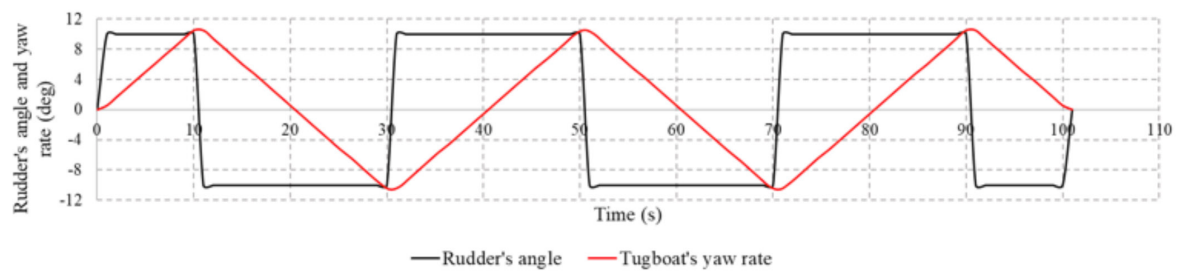

Figure 3: Zig zag graph of tugboat manoeuvre at rudder's angle $10^{\circ} / 10^{\circ}$

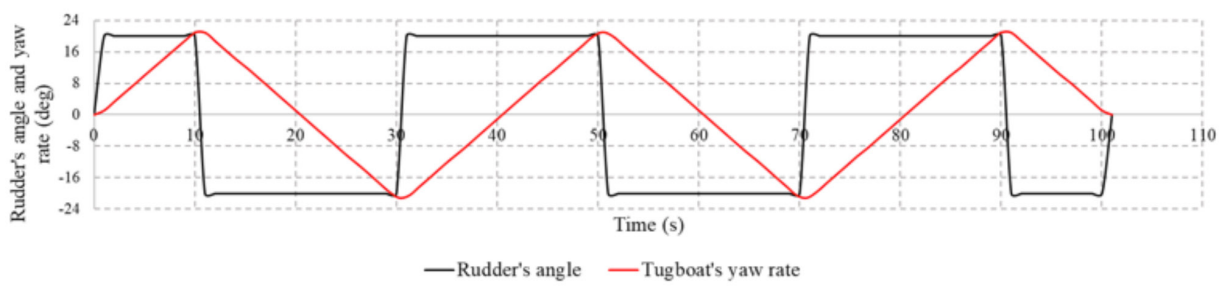

Figure 4: Zig zag graph of tugboat manoeuvre at rudder's angle $20^{\circ} / 20^{\circ}$

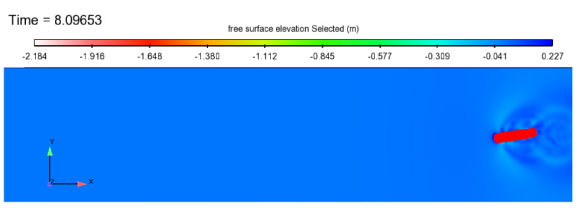

$1^{\circ} / 10^{\circ}(T=8.0 \mathrm{sec})$

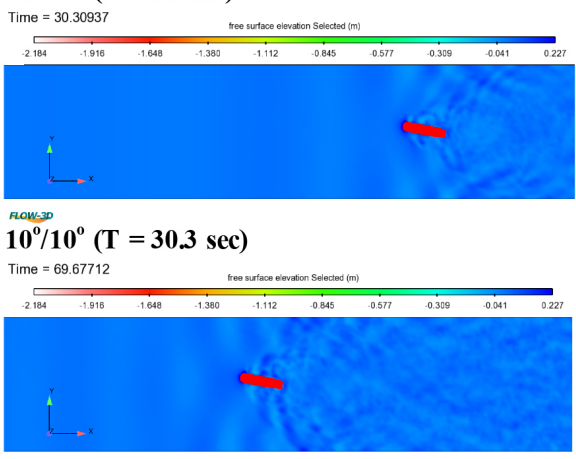

$10^{\circ} / 10^{\circ}(T=69.7 \mathrm{sec})$

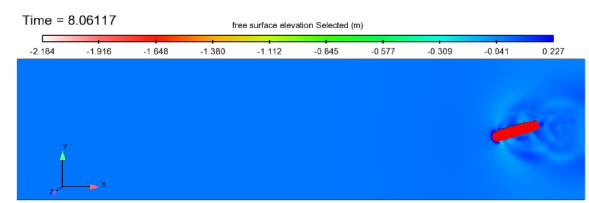

$20^{\text {Row } 20} / 20^{\circ}(\mathrm{T}=8.0 \mathrm{sec})$

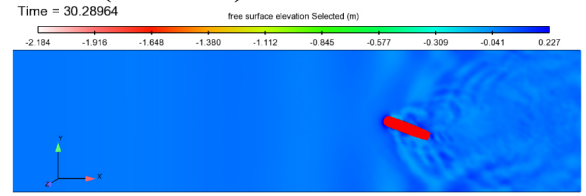

$2^{\circ} / 20^{\circ}(T=30.3 \mathrm{sec})$

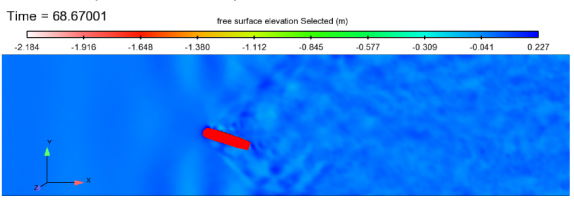

$20^{\circ} / 20^{\circ}(\mathrm{T}=69.7 \mathrm{sec})$

Universiti Malaysia Terengganu Journal of Undergraduate Research

Volume 3 Number 1, January 2021: 17-24 


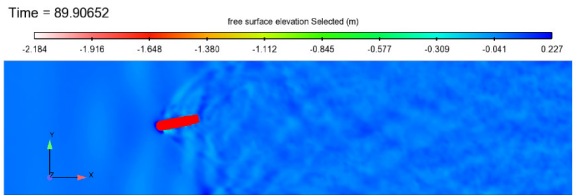

$10^{\circ} / 10^{\circ}(T=89.9 \mathrm{sec})$

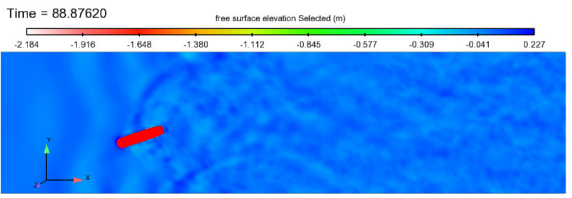

$\mathbf{2 0}^{\text {Rows. }} / 20^{\circ}(\mathrm{T}=\mathbf{8 9 . 9} \mathrm{sec})$

Figure 5: Free surface elevation of zig zag manoeuvre for $10^{\circ} / 10^{\circ}$ (left) and $20^{\circ} / 20^{\circ}$ (right) rudder's angle

Table 7: IMO criteria with zig zag manoeuvre

\begin{tabular}{lcccc}
\hline $\begin{array}{l}\text { Rudder's } \\
\text { angle }\end{array}$ & $\begin{array}{c}\text { First overshoot angle } \\
\left({ }^{\circ}\right)\end{array}$ & IMO criteria & $\begin{array}{c}\text { Second overshoot } \\
\text { angle }\left(^{\circ}\right)\end{array}$ & IMO criteria \\
\hline $10^{\circ} / 10^{\circ}$ & $0.6^{\circ}<20^{\circ}$ & comply & $0.6^{\circ}<25^{\circ}$ & comply \\
$20^{\circ} / 20^{\circ}$ & $1.08^{\circ}<20^{\circ}$ & comply & - & - \\
\hline
\end{tabular}

Effect of rudder's angle to the turning manoeuvrability of tugboat

The turning performance of tugboat was examined through nonlinear analysis, Figure 5. Based on the simulation results, tugboat complies with the IMO criteria both for its advance and tactical diameters except for the rudder's angle $\delta=15^{\circ}$ (tactical diameter value) as completely summarized in Table 8. The subsequent increase of $\delta$ from $20^{\circ}$ to $25^{\circ}$ and $35^{\circ}$ led to reduce the advance diameter of tugboat by $7 \%$ and $11 \%$, respectively. The similar tendencies showed that the tactical diameter also significantly reduced about $20 \%$ and $41 \%$, respectively. It can be inferred that the increase of $\delta$ has more considerable effect to the magnitude of the tactical diameter than advance diameter of tugboat.

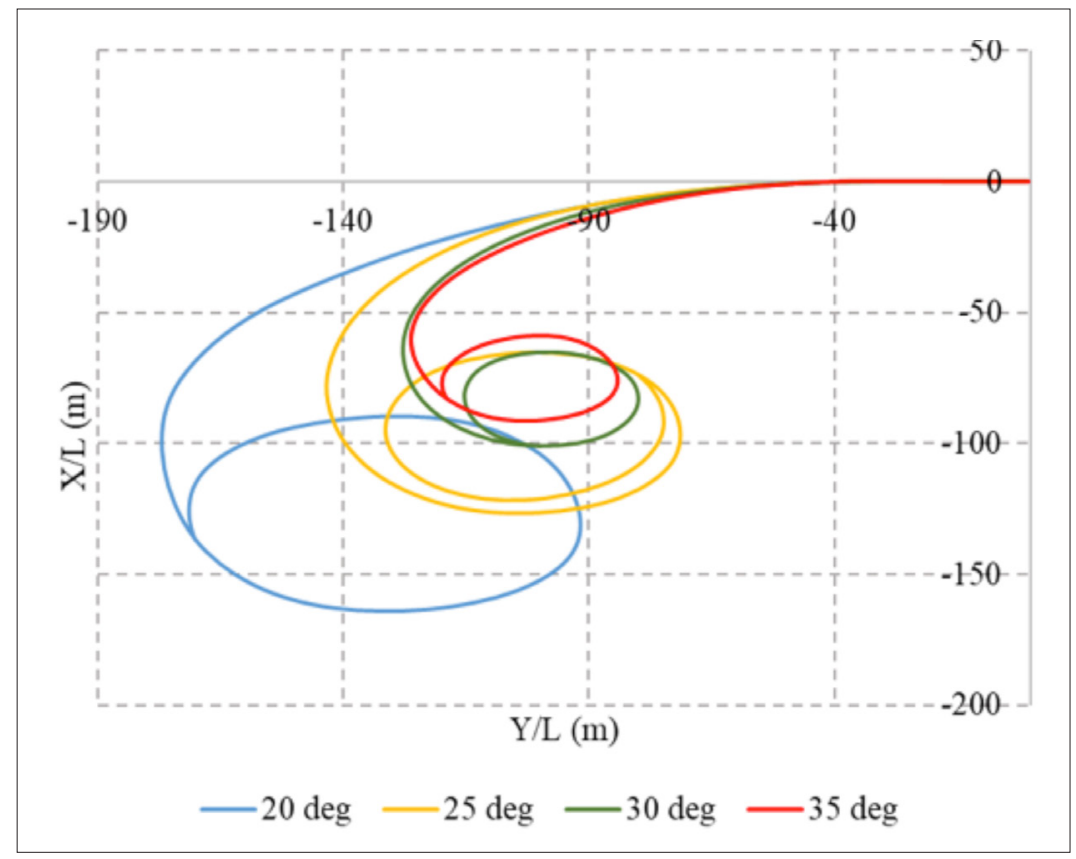

Figure 5: Graph of turning diameter at various rudder's angles 
Table 8: IMO criteria with turning manoeuvre at various rudder's angles

\begin{tabular}{ccccc}
\hline Rudder's angle $\left(^{\circ}\right)$ & $\begin{array}{c}\text { Advance } \\
\text { diameter }(\mathrm{m})\end{array}$ & IMO criteria & $\begin{array}{c}\text { Tactical diameter } \\
(\mathrm{m})\end{array}$ & IMO criteria \\
\hline 20 & $3.6 \mathrm{~L}<4.5 \mathrm{~L}$ & OK & $4.5 \mathrm{~L}<5 \mathrm{~L}$ & OK \\
25 & $2.7 \mathrm{~L}<4.5 \mathrm{~L}$ & OK & $3.2 \mathrm{~L}<5 \mathrm{~L}$ & OK \\
30 & $2.4 \mathrm{~L}<4.5 \mathrm{~L}$ & OK & $2.5 \mathrm{~L}<5 \mathrm{~L}$ & OK \\
35 & $2.3 \mathrm{~L}<4.5 \mathrm{~L}$ & OK & $2.3 \mathrm{~L}<5 \mathrm{~L}$ & OK \\
\hline
\end{tabular}
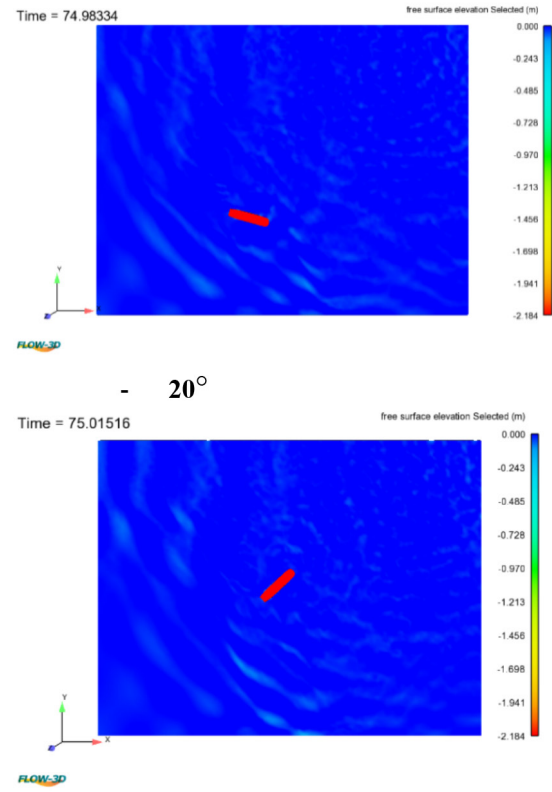

(c) $30^{\circ}$

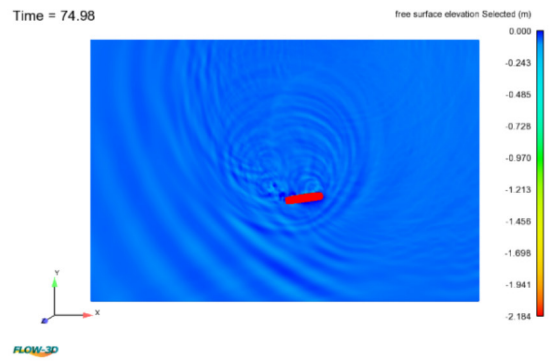

(b) $25^{\circ}$

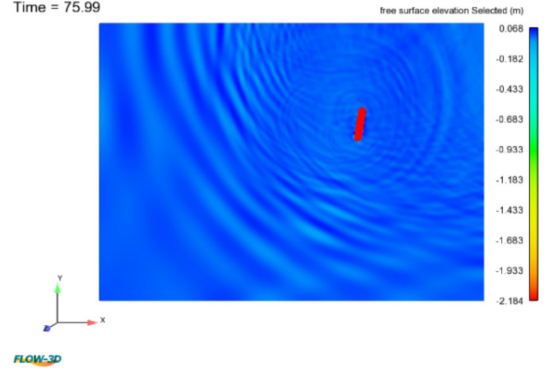

(e) $35^{\circ}$

Figure 7: Free surface elevation of complete turning circle at rudder's angle (a) $20^{\circ}$, (b) $25^{\circ}$, (c) $30^{\circ}$ and (d) $35^{\circ}$

\section{Effect of Forward Speed to the Manoeuvrability of Tugboat}

Increase of forward speed from 7 knots to 9 knots significantly decreased the turning diameter of ship. Higher forward speed with large angular velocity during manoeuvring will reduce the stability of the ship. 
Figure 7: Graph of turning diameter at various forward speed

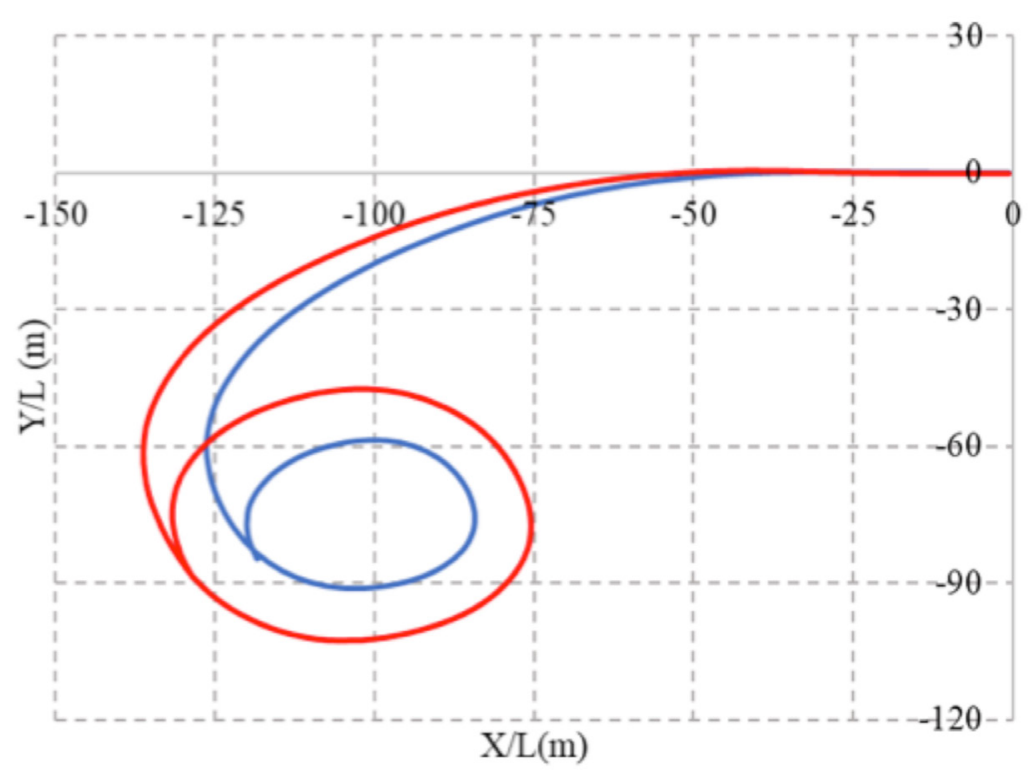

-8 knots -9 knots

Table 9: IMO criteria with turning maneuver at various forward speed

\begin{tabular}{ccccc}
\hline $\begin{array}{c}\text { Forward speed } \\
(\text { knot })\end{array}$ & $\begin{array}{c}\text { Advance } \\
\text { diameter }(\mathbf{m})\end{array}$ & IMO criteria & $\begin{array}{c}\text { Tactical } \\
\text { diameter }(\mathbf{m})\end{array}$ & IMO criteria \\
\hline 8 & $1.75 \mathrm{~L}<4.5 \mathrm{~L}$ & OK & $2.27 \mathrm{~L}<5 \mathrm{~L}$ & OK \\
9 & $2.63 \mathrm{~L}<4.5 \mathrm{~L}$ & OK & $2.54 \mathrm{~L}<5 \mathrm{~L}$ & OK \\
\hline
\end{tabular}
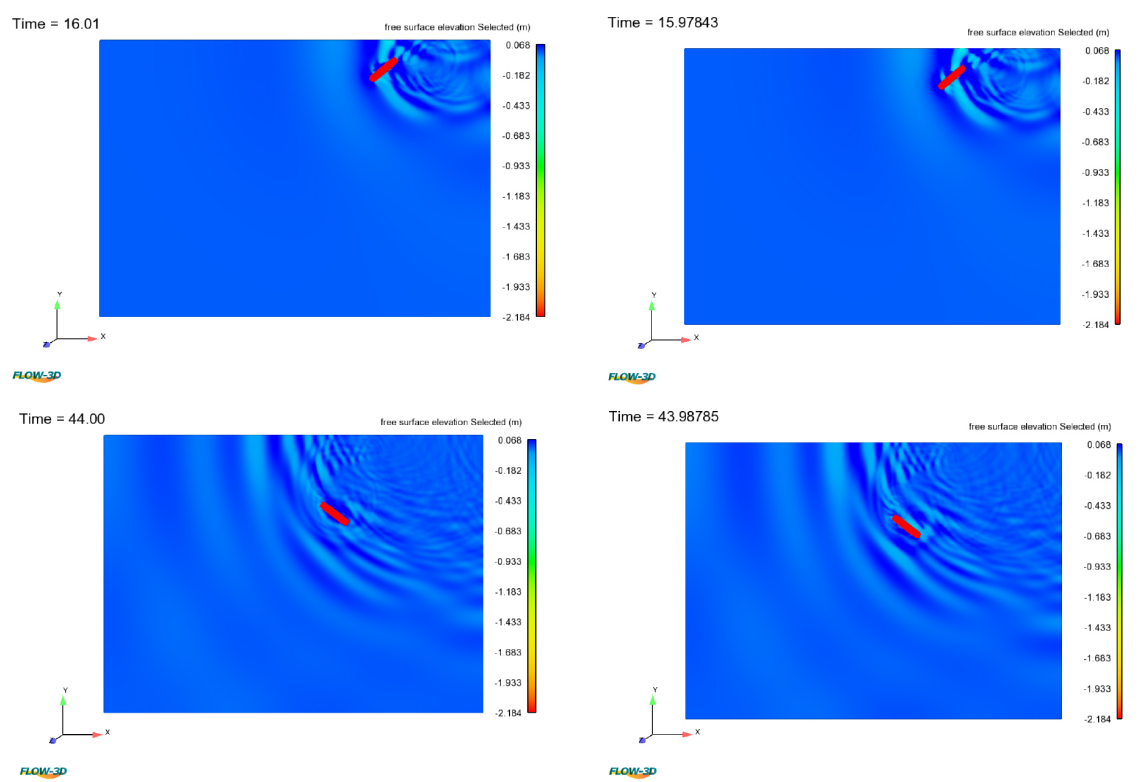

Universiti Malaysia Terengganu Journal of Undergraduate Research Volume 3 Number 1, January 2021: 17-24 

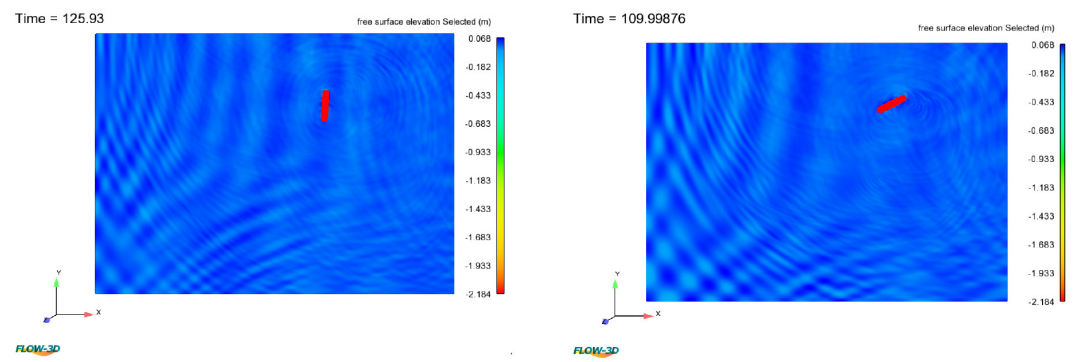

Figure 9: Free surface elevation of complete turning circle at 8 knots (left) and 9 knots (right)

\section{Conclusion}

The Computational Fluid Dynamics (CFD) analysis on manoeuvrability of a tugboat was successfully performed using the Flow 3D version 11.2 software. The effects of various rudder's angle and various operational speed have been appropriately investigated. Based on nonlinear analyses, several conclusions of manoeuvring prediction for tugboat manoeuvre can be drawn as follows;

- The advance diameter with the rudder's angle of $15^{\circ}$ does not comply with the IMO criteria.

- The advance and tactical diameters with the rudder's angle of $25^{\circ}$ and $35^{\circ}$ comply with the IMO criteria.

- The zig-zag manoeuvring simulation showed that the first and second overshoot angles of $10^{\circ} / 10^{\circ}$ and $20^{\circ} / 20^{\circ}$ are acceptable with the IMO criteria.

In nutshell, the manoeuvring performance of a ship will be strongly influenced by its rudder(s). Prior to ship construction, a methodology to evaluate the manoeuvring characteristics of tugboat is established with several different parameters to be considered namely forward speed and angular velocity by using FLOW3D free-running model approach. Increased of ship rudder's angle generally decreased the turning diameter of manoeuvring. While increased of forward speed during operation will increased the turning diameter of ship. Proper parameters during turning will increase the effectiveness of ship manoeuvring to avoid undesired accident.

\section{Acknowledgements}

The authors would like to thank a great appreciation as well to the Universiti Malaysia Terengganu for its support upon the completion of this research.

\section{References}

Fitriadhy, A., Abdullah, S., Hairil, M., Ahmad, M., \& Jusoh, A. (2019). Optimized modelling on lateral separation of twin pontoon-net floating breakwater. Journal of Mechanical Engineering and Sciences, 13(4), 5764-5779.

Hirano, M. (1980). On the calculation method of ship maneuvering motion at initial design phase (in Japanese). Journal of the Society of Naval Architects of Japan, 59, 71-81.

Ueno, M., T. Nimura, \& H. Miyazaki (2003). Experimental study on maneuvering motion of a ship in waves. Proceedings of the International Conference on Marine Simulation and Ship Manoevrability.

Yasukawa, H. (2006). Simulations of ship maneuvering in waves. Journal of the Japan Society of Naval Architects and Ocean Engineers, 4, 127-136. 